\title{
CRACK INITIATION STUDIES OF MA 760 DURING HIGH TEMPERATURE LOW CYCLE FATIGUE
}

\author{
A. Hynnä*, V.-T. Kuokkala** and P. Kettunen* \\ Tampere University of Technology \\ *Institute of Materials Science \\ **Center for Electron Microscopy \\ P.O.Box 589, FIN-33101 Tampere, FINLAND
}

\begin{abstract}
The objective of this work was to investigate the high temperature low cycle fatigue properties of a mechanically alloyed and oxide dispersion strengthened Ni-base superalloy MA 760. The push-pull fatigue tests at different strain rates using specimens of two different grain orientations (longitudinal, $\mathrm{L}$ and long transverse, LT) were carried out at temperatures of $650^{\circ} \mathrm{C}, 950^{\circ} \mathrm{C}$ and $1050^{\circ} \mathrm{C}$. The control parameter in all tests was the total strain amplitude. After the tests, detailed fractographical and microstructural studies using optical microscopy, scanning electron microscopy and analytical electron microscopy were carried out. In this paper, the main emphasis is placed on the fatigue crack initiation mechanisms and their dependence of fatigue test parameters and grain orientations. Also, a brief overview of the mechanical behavior of MA 760 during high temperature cyclic straining will be presented.
\end{abstract}

\section{Introduction}

Oxide dispersion strengthened (ODS) superalloys form one of the new materials groups developed in search for materials with better properties in extreme operating conditions. They maintain their high strength and good corrosion resistance at higher temperatures better than conventional superalloys, and are therefore of great interest, for example, to designers of gas turbine engines (Ref. 1). ODS superalloys are produced by mechanical alloying process (Ref. 2) followed by conventional processing and heat treating processes, including extrusion, hot rolling, recrystallization- and $\gamma^{\prime}$-precipitation heat treatments. The excellent properties of ODSalloys are due to the very fine dispersion of stable, incoherent oxide particles, formed during the mechanical alloying process. These particles act as barriers to the movement of dislocations (Ref. 3). ODS Ni- base superalloys can also be strengthened by coherent $\gamma^{\prime}$-precipitates. The $\gamma^{\prime}$-strengthening is acting effectively at lower temperatures than dispersion strengthening, which becomes dominant at temperatures above $1000^{\circ} \mathrm{C}$ (Ref. 4). After recrystallization heat treatment, the grain structure of ODS- alloys is very coarse and the grain aspect ratio is large. Together with serrated grain boundaries, the microstructures that develop result in properties that are necessary for high temperature service, where the amount of transverse grain boundaries should be minimized (Ref. 5).

The design criteria for components made of ODS- alloys are not up to date and sufficient due to the lack of experimental data. In addition, the high temperature micromechanisms and microstructures produced by the deformation processes are not well enough established. This is especially true for the MA 760, a modified more corrosion resistant version of the well known alloy MA 6000 . In this paper, we report the low cycle fatigue properties of MA 760 at elevated temperatures putting the main emphasis on the crack initiation and crack propagation mechanisms.

\section{Material and experimental techniques}

The test material, a mechanically alloyed Ni-base ODS superalloy MA 760, was delivered by INCO Alloys Ltd., Hereford, U.K. The material was produced in the form of bars of rectangular crosssections. The bars were of two different cross-sections, SCS $(200 \mathrm{~mm} \times 600 \mathrm{~mm})$ and LCS $(320 \mathrm{~mm} \times 950 \mathrm{~mm})$. The SCS-bars were completely produced at Hereford, whereas the final recrystallization heat-treatment of the LCS-material was performed at Asea Brown Boveri, Baden, Switzerland. Compositions of the delivered bars are presented in Table I. The final heat treatment of the SCS bar was $0.5 \mathrm{~h}$ at $1100^{\circ} \mathrm{C}$, furnace cooling with $60^{\circ} \mathrm{C} / \mathrm{h}$ to $600^{\circ} \mathrm{C}$, followed by uncontrolled furnace cooling. The heat treatment procedure for the LCS bar was the same with the exception that the solutioning temperature was $1120^{\circ} \mathrm{C}$.

Table I Compositions of the delivered bars

\begin{tabular}{|c|c|c|}
\hline Element & SCS, [wt-\%] & LCS, [wt-\%] \\
\hline $\mathrm{C}$ & 0.043 & 0.042 \\
\hline $\mathrm{Si}$ & 0.04 & 0.05 \\
\hline $\mathrm{Fe}$ & 1.02 & 1.04 \\
\hline $\mathrm{Cr}$ & 19.66 & 19.79 \\
\hline $\mathrm{Al}$ & 5.97 & 5.93 \\
\hline $\mathrm{Mo}$ & 1.92 & 1.96 \\
\hline $\mathrm{S}$ & 0.003 & 0.003 \\
\hline $\mathrm{Zr}$ & 0.14 & 0.14 \\
\hline $\mathrm{N}$ & 0.284 & 0.286 \\
\hline $\mathrm{O}$ & 0.54 & 0.6 \\
\hline $\mathrm{W}$ & 3.5 & 3.5 \\
\hline $\mathrm{B}$ & $110 \mathrm{ppm}$ & $110 \mathrm{ppm}$ \\
\hline $\mathrm{P}$ & $<0.005$ & $<0.005$ \\
\hline $\mathrm{Ni}$ & $\mathrm{Bal}$ & $\mathrm{Bal}$. \\
\hline $\mathrm{Y}_{2} \mathrm{O}_{3}$ & 1.03 & 1.03 \\
\hline & & \\
\hline
\end{tabular}


The SCS material was aimed for mechanical testing in the Ldirection and the LCS material in the LT-direction. The orientation of the fatigue specimens relative to the grain orientation and the extrusion direction are presented in Figure 1.

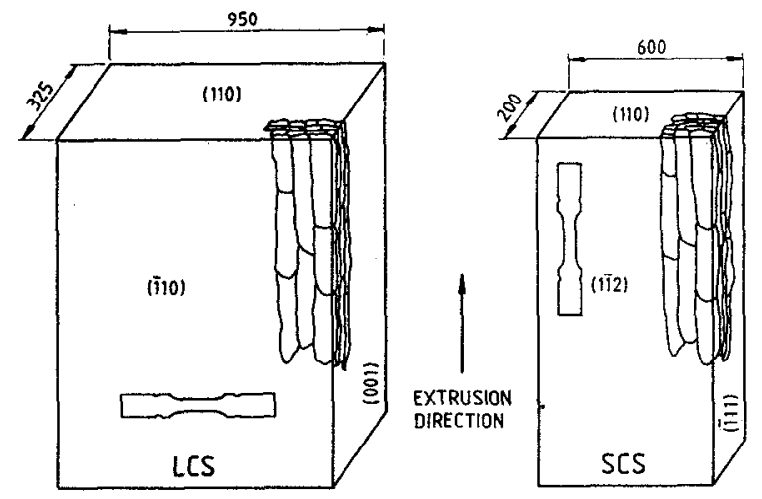

Figure 1. The orientation of the fatigue specimens in the SCS- and LCS-bars relative to the grain orientation and extrusion direction. Fatigue specimens are not in scale.

The push-pull fatigue tests were carried out with a MTS TestStar $^{\mathrm{TM}}$ microcomputer based servohydraulic materials testing system. In all tests, $\Delta \varepsilon_{t}$ was used as a control parameter. A symmetrical triangular wave shape $(R=-1)$ was applied using the strain rates of $0.5 \mathrm{~s}^{-1}$ (fast, F) or $0.05 \mathrm{~s}^{-1}$ (slow, S). The tests were carried out at three different temperatures specified in Table II. A more detailed description of the testing techniques is presented in Ref. 6.

\section{$\underline{\text { Results and discussion }}$}

Mechanical behavior

A summary of the fatigue test parameters and test results is shown in Table II. The stress amplitudes $\sigma_{\max }, \sigma_{\min }$ and $\Delta \sigma / 2$ were measured from the cycle recorded at half life $\mathrm{N}_{\mathrm{f}} / 2$. As a failure criterion, a $20 \%$ stress drop was used.

During cyclic straining, there is no observable cyclic hardening or cyclic softening in MA 760, except during the crack growth period at the very end of each test. Also the loop shapes stay practically unchanged during cyclic straining. These observations indicate that the alloy is in a cyclically stable state from the initial cycles onwards, i.e., a stable dislocation configuration is generated at the beginning of the test. Also other microstructural changes during fatigue appear to be negligible.

The ductility of MA 760 changes markedly over the temperature region covered in this study. Therefore, in the Coffin-Manson plot, the relative positions of the data points at $650{ }^{\circ} \mathrm{C}$ change dramatically when total strain amplitude is replaced by plastic strain amplitude. If the comparison of fatigue lives between different temperatures is made purely on the basis of CoffinManson plots, one may enter into erroneous conclusions. Therefore, the comparison should be based on $\Delta \varepsilon_{\mathrm{f}}$ or $\Delta \sigma / 2$ vs. $\mathrm{N}_{\mathrm{f}}$ plots. On the basis of $\Delta \varepsilon_{t}$ vs. $N_{f}$ plots, the increasing creep component shortens the fatigue life. At comparable test parameter values the fatigue lives of the LT-samples are in most cases shorter than the fatigue lives of the L-samples. More information of the mechanical behavior of the alloy MA760 can be found in Ref. 7 .

Table II Numerical values recorded in the fatigue tests.

\begin{tabular}{|c|c|c|c|c|c|c|c|c|c|c|}
\hline $\begin{array}{c}\text { Test } \\
\text { No. }\end{array}$ & $\begin{array}{c}\text { Specimen } \\
\text { orientation }\end{array}$ & $\begin{array}{c}\mathrm{T} \\
{\left[{ }^{\circ} \mathrm{C}\right]}\end{array}$ & $\begin{array}{c}\dot{\varepsilon} \\
{\left[\% \mathrm{~s}^{-1}\right]}\end{array}$ & $\begin{array}{c}\Delta \varepsilon_{\mathrm{t}} \\
{[\%]}\end{array}$ & $\begin{array}{c}\Delta \varepsilon_{\mathrm{pl}} \\
{[\%]}\end{array}$ & $\begin{array}{c}\Delta \varepsilon_{\mathrm{e}} \\
{[\%]}\end{array}$ & $\begin{array}{c}\sigma_{\max } \\
{[\mathrm{MPa}]}\end{array}$ & $\begin{array}{c}\sigma_{\min } \\
{[\mathrm{MPa}]}\end{array}$ & $\begin{array}{c}\Delta \sigma / 2 \\
{[\mathrm{MPa}]}\end{array}$ & $\begin{array}{c}\mathrm{N}_{\mathrm{f}} \\
{[\mathrm{cycl}]}\end{array}$ \\
\hline 1 & $\mathrm{~L}$ & 650 & 0.5 & 1.0 & 0.1 & 0.9 & 850 & -950 & 900 & 792 \\
\hline 2 & $\mathrm{~L}$ & 650 & 0.5 & 0.8 & 0.04 & 0.76 & 705 & -780 & 742.5 & 3925 \\
\hline 3 & $\mathrm{~L}$ & 650 & 0.5 & 0.6 & 0.01 & 0.59 & 560 & -575 & 567.5 & 16320 \\
\hline 4 & $\mathrm{~L}$ & 950 & 0.5 & 1.0 & 0.51 & 0.49 & 310 & -340 & 325 & 570 \\
\hline 5 & $\mathrm{~L}$ & 950 & 0.5 & 0.8 & 0.35 & 0.45 & 275 & -305 & 290 & 960 \\
\hline 6 & $\mathrm{~L}$ & 950 & 0.5 & 0.6 & 0.2 & 0.4 & 250 & -270 & 260 & 4575 \\
\hline 7 & $\mathrm{~L}$ & 950 & 0.05 & 1.0 & 0.49 & 0.51 & 290 & -300 & 295 & 415 \\
\hline 8 & $\mathrm{~L}$ & 950 & 0.05 & 0.8 & 0.34 & 0.46 & 270 & -285 & 277.5 & 880 \\
\hline 9 & $\mathrm{~L}$ & 950 & 0.05 & 0.6 & 0.19 & 0.41 & 240 & -265 & 252.5 & 3945 \\
\hline 10 & $\mathrm{~L}$ & 1050 & 0.5 & 0.8 & 0.55 & 0.25 & 160 & -180 & 170 & 395 \\
\hline 11 & $\mathrm{~L}$ & 1050 & 0.5 & 0.8 & 0.55 & 0.25 & 160 & -180 & 170 & 595 \\
\hline 12 & $\mathrm{~L}$ & 1050 & 0.5 & 0.6 & 0.35 & 0.25 & 170 & -195 & 182.5 & 1025 \\
\hline 13 & $\mathrm{~L}$ & 1050 & 0.5 & 0.35 & 0.11 & 0.24 & 150 & -160 & 155 & 6925 \\
\hline 14 & $\mathrm{~L}$ & 1050 & 0.5 & 0.25 & 0.01 & 0.24 & 160 & -180 & 170 & 67300 \\
\hline 15 & $\mathrm{~L}$ & 1050 & 0.05 & 0.8 & 0.55 & 0.25 & 170 & -190 & 180 & 305 \\
\hline 16 & $\mathrm{~L}$ & 1050 & 0.05 & 0.6 & 0.36 & 0.24 & 160 & -180 & 170 & 620 \\
\hline 17 & $\mathrm{~L}$ & 1050 & 0.05 & 0.35 & 0.1 & 0.25 & 160 & -170 & 165 & 3350 \\
\hline 18 & LT & 950 & 0.5 & 1.0 & 0.66 & 0.34 & 285 & -300 & 292.5 & 600 \\
\hline 19 & LT & 950 & 0.5 & 0.6 & 0.3 & 0.3 & 250 & -275 & 262.5 & 2105 \\
\hline 20 & LT & 950 & 0.5 & 0.45 & 0.15 & 0.3 & 240 & -260 & 250 & 6770 \\
\hline 21 & LT & 1050 & 0.5 & 1.0 & 0.8 & 0.2 & 140 & -160 & 150 & 105 \\
\hline 22 & LT & 1050 & 0.5 & 0.6 & 0.42 & 0.18 & 145 & -155 & 150 & 585 \\
\hline 23 & LT & 1050 & 0.5 & 0.45 & 0.25 & 0.2 & 145 & -150 & 147.5 & 1125 \\
\hline 24 & LT & 1050 & 0.05 & 1.0 & 0.79 & 0.21 & 140 & -145 & 142.5 & 110 \\
\hline 25 & LT & 1050 & 0.05 & 0.6 & 0.4 & 0.2 & 135 & -155 & 145 & 580 \\
\hline 26 & LT & 1050 & 0.05 & 0.45 & 0.26 & 0.19 & 145 & -150 & 147.5 & 1280 \\
\hline & & & & & & & & & & \\
\hline
\end{tabular}




\section{Crack initiation}

During low cycle fatigue, several different damage accumulation processes are active simultaneously, and the crack initiation takes place at the weakest link in the microstructure. In the L-samples, the initiation sites fall into several categories. The most frequent initiation site secms to be a longitudinal grain boundary crossing the specimen surface, in this case the initiation site can be considered to be at the specimen surface. In Figure 2, a SEM image of a typical example falling into this category is presented. The magnification of this image is rather low and the boundary indicated by an arrow is not easily visible, but the opened boundary is more clearly visible in Figure 3 taken from the surface of sample 7. Convincing evidence of crack initiation the opened boundary is also given in Figure 3, which clearly illustrates secondary cracking at the boundary crossing the specimen surface. Crack initiation at these boundaries is enhanced by oxidation effects. The high energy level, carbides and $\gamma^{\prime}$-film along the boundaries (Ref. 8) promote the oxidation of the boundaries.

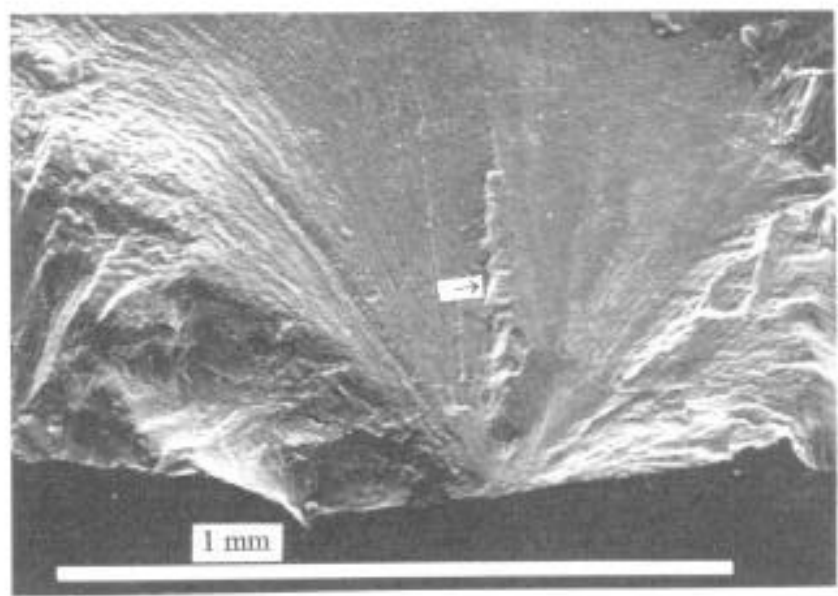

Figure 2. Fracture initiation site in sample 7.

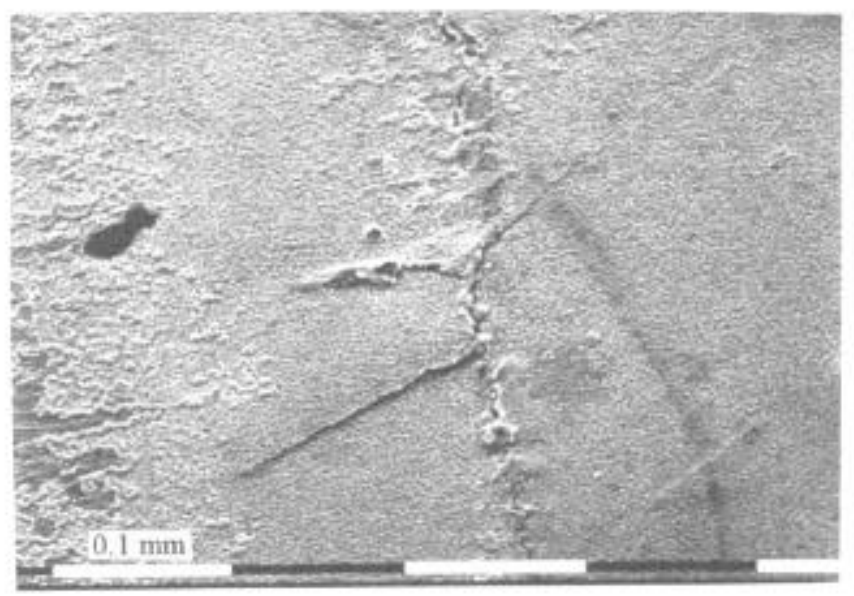

Figure 3. Longitudinal opened boundary on the surface of specimen 7. Crack initiation takes place at the opened boundary.
Occasionally individual small grains or a group of small grains were also observed to act as initiation sites in L-samples. These grains lie near the specimen surface, in some cases extending to the surface itself. However, in all observed cases the distance to the free surface was no more than $0.1 \mathrm{~mm}$. The reason for the easy crack initiation at these sites can be understood by noting that the boundaries around small grains are very susceptible to the opening phenomenon (Ref. 9). It is believed (Ref. 10) that one reason for the susceptibility of the fine grains to fatigue damage is related to the differences in the crystallographic orientation between the large and small grains, resulting in high local stress concentrations at fine grain boundaries during loading. Also, if the high angle boundaries associated with the small grains extend to the specimen surface, they will be favorable sites for oxidation damage. In the L-samples crack initiation at subsurface inclusions was detected in two cases. In sample 6 an Al-rich inclusion containing $5 \%$ copper was found at the initiation site, and in sample 16 a $\mathrm{Cr}$-rich inclusion had initiated the crack.

The crack initiation sites in the LT-samples were only, except for test 25 , at transverse boundaries crossing the specimen surface as illustrated in Figure 4. The initiation sites were similar to those found in the L-samples, the only difference being the orientation of the boundaries. Only in one case initiation at an inclusion clearly inside the specimen was observed. In this case, the observed Alrich defect was an exceptionally large one, approximately $0.5 \mathrm{~mm}$ in all three dimensions, and situated in a narrow grain with a width of approximately the same as the diameter of the inclusion.

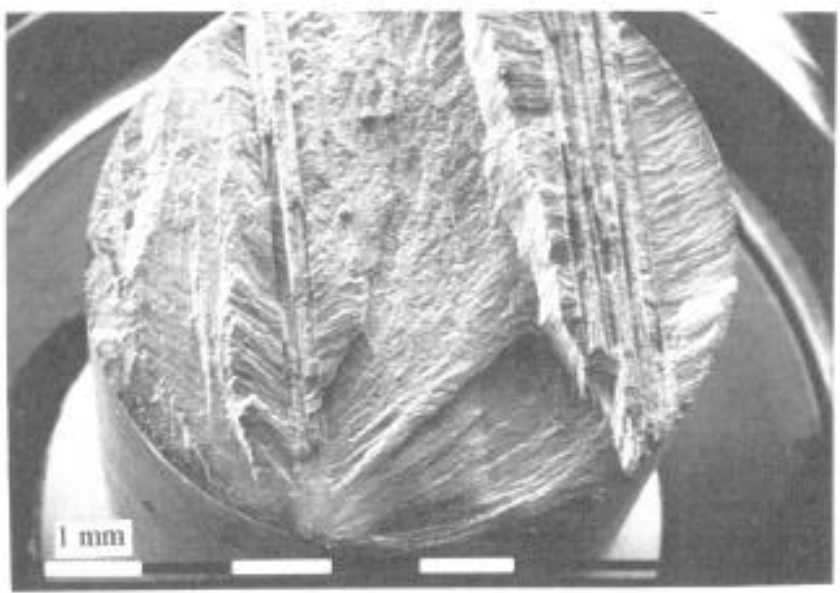

Figure 4. Crack initiation at transverse grain boundary crossing the surface in sample 19 .

On the basis of the crack initiation studies it may be concluded that the boundaries are the weakest link in the alloy MA 760. When the initiation of a crack was associated with an inclusion or small grains, no drastic effect on the fatigue life, expressed e.g. as Coffin-Manson-type plots, can be found. The fatigue lives of the LT-samples are shorter to those of the L-samples, a phenomenon clearly related to the damage accumulation during the crack initiation period. This leads to the conclusion that the damage accumulation at the sites of the intersecting boundaries and free surface in LT-samples is faster than in L-samples. One possible explanation for this behavior is, if oxidation effects are assumed to be identical, that there exist higher stress concentrations at crack initiation sites in the case of LT-samples. Indeed, this may be the 
case, because in each of the LT-samples there existed at least one packet of narrow grains crossing the free surface, as illustrated also in Figure 4. The boundaries of these grains were of the high angle type, an observation based on the large contrast differences between individual grains. In fact, the crack initiation site in every LT-sample (except sample 25) was associated with these packets of fine grains. It can be assumed that the local stress concentrations are highet at these sites compared to the situation in L-samples, where the initiation site was associated with a single boundary of low angle type. This explanation could account for the smaller strain rate dependence (a smaller role of time dependent damage accumulation) in LT-samples compared to the L-samples. Also, it is possible that the damage accumulation due to oxidation at these high angle boundaries is faster than at (in most of the cases) low angle boundaries in L-samples.

\section{Surface studies}

The aim of the surface studies was to investigate the effects on the specimen surface that could be involved in the crack initiation processes. A common phenomenon observed was the opening of the boundaries at the specimen surface, acting often as a site for crack initiation. Other surface effects include oxidation of the boundaries of small grains and oxidation of inclusions. However, obviously the damaging effects of these changes are small compared to the opened boundaries, because they were only occasionally involved in the crack initiation, although the opening susceptibility of the boundaries around small grains seems to be higher than that of the boundaries between large grains. The oxidation of these sites, as well as the overall oxidation of the surface, was negligible at $650^{\circ} \mathrm{C}$ but became more pronounced at higher temperatures.

A general feature in all samples fatigued at $950{ }^{\circ} \mathrm{C}$ and at $1050{ }^{\circ} \mathrm{C}$ was the presence of unevenly spaced slip lines (max. length $2 \mathrm{~mm}$ measured along the specimen surface). Also the presence of short, ca. $0.1-0.5 \mathrm{~mm}$, slip line piles was observed. The amount of the lines clearly increased with decreasing strain rate. Also the increasing temperature had the same, although not so pronounced, effect. This behavior has been previously reported by Elzey and Arzt (Ref. 11) for MA 6000 , but only at high plastic strain amplitudes. Generally the dispersoid particles are regarded to promote slip dispersal compared to non-ODS alloys. However, it should be pointed out that the density of the slip lines in the gauge length was not generally uniform. As a rule, most of the specimen surface was completely free of slip lines and the lines concentrated into a relatively narrow band near the fracture surface. In the tests conducted at $950^{\circ} \mathrm{C}$, only relatively few single lines in the bands of width less than one millimeter were detected, and generally they were associated with the boundaries of fine grains, as illustrated in Figure 5. The band width increased with increasing temperature and decreasing strain rate. The existing lines form a site for microcrack initiation, but normally these microcracks do not determine the fatigue life of the sample. Rather it seems that the primary crack is initiated at a point where an individual slip line crosses an opened boundary, as illustrated in the Figure 6. From the observations mentioned above, the deformation at $950^{\circ} \mathrm{C}$ seems to be much more concentrated into fewer slip lines than at $1050^{\circ} \mathrm{C}$. According to these results the formation tendency of the slip lines becomes marked at $1050^{\circ} \mathrm{C}$ (above $\gamma^{\prime}$ solidus). Also the lowering of the strain rate seems to have an effect of the same trend.

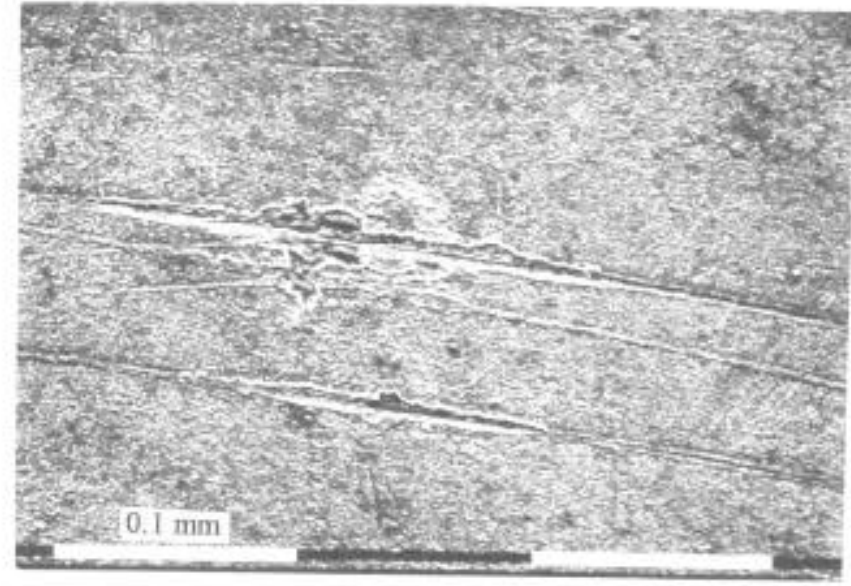

Figure 5. Slip line formation associated with the fine grains in sample 5 .

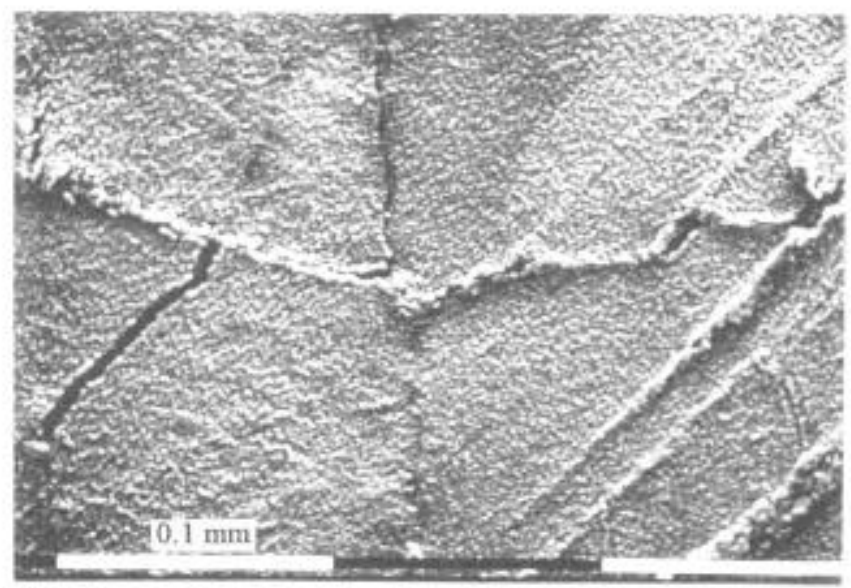

Figure 6. The intersection of slip lines and an opened boundary in sample 5.

The slip lines can extend themselves over considerably long distances along the surface and secondary stage I cracks initiate at these sites. The cracks grow transgranularly and the longest observed cracks extended $50 \mu \mathrm{m}$ into the grains. In the tests conducted at $950^{\circ} \mathrm{C}$, this short crack growth behavior revealed one of the deformation mechanisms to be $\gamma^{\prime}$ cutting. This is illustrated in Figure 7, in which the tip of a $15 \mu \mathrm{m}$ deep crack is presented. Clearly at the very tip of the crack, cut $\gamma$ particles are present, indicated by an arrow. Occasionally slip lines were observed in the sectioned surface of the samples and only in the etched condition. In these cases the lengths of these lines varied from 10 to $30 \mu \mathrm{m}$. Also in these areas of intense deformation, the process of $\gamma$ cutting was clearly detectable. The slip lines were not observed in series L650F tests, but in all other tests they were defected occasionally in the longitudinal section of the samples. It is worth mentioning that this could also be an etching artifact caused by the $\gamma^{\prime}$ dropping-off from the etched surface. However, milder etching conditions did not reveal a marked increase of the slip lines and therefore it is assumed that the dropping-off does not play a significant role. A general view of the area of an abnormally high density of slip lines is presented in Figure 8. 


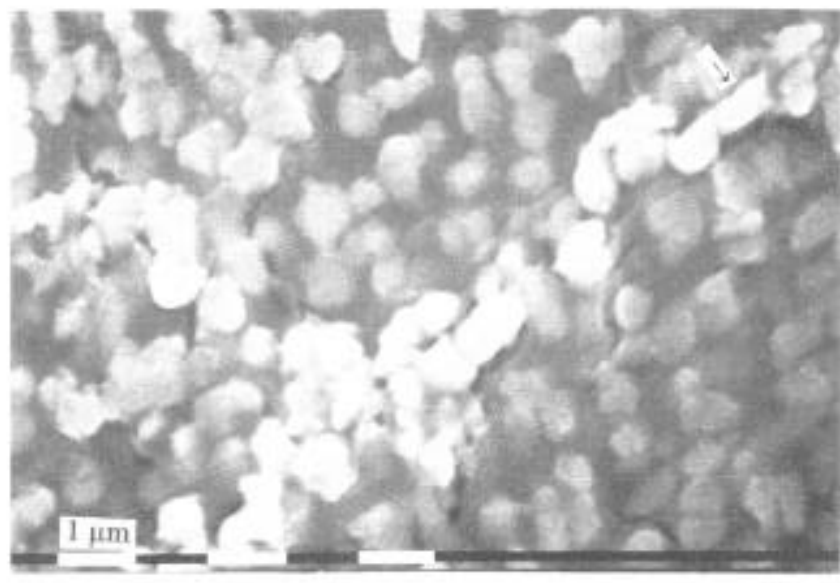

Figure 7. Tip of a microcrack in sample 6.

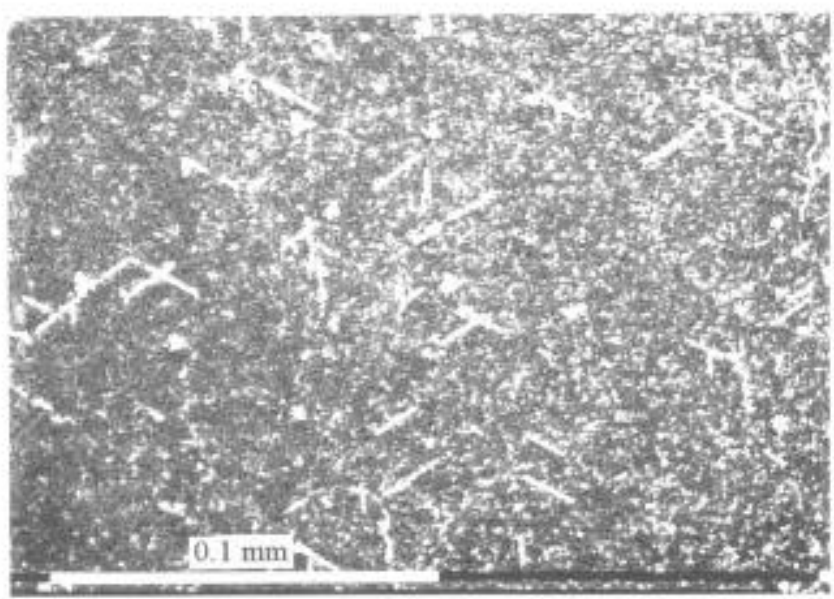

Figure 8. Slip lines in sample 6.

The strong [110] texture permits a more detailed analysis of the active slip planes to be performed. The nearly longitudinal slip lines in Figure 8 are perpendicular to the plane $(110)$ and therefore they are traces of either conjugate $(1 \overline{1} 1)$ or cross $(1 \overline{1} \overline{1})$ slip planes. If it is assumed that the slip plane is $(1 \overline{1} 1)$, then the other possible slip planes are critical (111), primary (11) and cross $(1 \overline{1} \overline{1}$ ). If the second altemative holds, then the other possible planes are critical (111), conjugate $(1 \overline{1} 1)$ and primary $(11 \overline{1})$ Normally the indexing of the slip line patterns is based on determining the loading axis and side surface orientations by, e.g. Laue X-ray technique. This tedious procedure is commonly applied to single crystals, but it can be applied to large grained materials also. However, the Laue method was not used in this study, but instead an approximate method was applied. The procedure in this method was as follows: 1) measurement of the angles between traces of three $\{111\}$-type slip planes on a longitudinal section of unknown indeces, 2) calculation of the angles between the trace vectors of $\{111\}$-type planes on different hkl-planes, and 3) comparison of the calculated angles with the measured ones using a computer program developed for this purpose (Ref. 12). The angles of the traces of the other two planes with the almost vertical one were both measured and found to be 58 degrees. In the calculations, error limits of \pm 1 degree for the measured angles were used and the value of 10 for the highest index of the unknown plane was chosen. It was found that the indices of the unknown plane were of type $\left\{\begin{array}{lll}10 & 10 & 9\end{array}\right\}$. The calculations indicated that the two inclined slip planes must be the primary and the critical slip plane with angles of 57.3 degrees with the vertical $\{111\}$-type plane.

The Schmid factor for the primary slip system (111) [101], as well as for the critical slip system $(111)[10 \overline{1}]$ is $1 / \sqrt{6} \approx 0.408$. On the other hand, for the conjugate slip system $(1 \overline{1} 1)[110]$ and for the cross slip system $(1 \overline{1} \overline{1})[101]$ the factor is zero, so that only the primary and the critical slip systems can be active in the SCS material. The vertical slip lines observed are thus probably an indication of the dislocation reactions between the primary and the critical slip planes.

\section{Conclusions}

1. Most of the cyclic life of MA 760 is spent in the fatigue initiation stage. The crack initiation is enhanced by the oxidation of the boundaries crossing the free surface of the sample, which in most of the cases act as crack initiation sites.

2. The inferior fatigue life, as well as the minor strain rate effects on the fatigue life of the LT-samples compared to the L-samples are due to higher stress concentrations at the fatigue initiation sites. This, in tum, results from the differences in the crack initiation sites. In the L-samples the initiation site in most cases is the low angle boundary crossing the specimen surface. In the LT-samples, the initiation site most commonly is a packet of narrow grains separated by high angle boundaries and crossing the specimen surface.

3. The tendency for heavier slip line formation in the specimen surface increased with increasing temperature and decreasing strain rate. At lower temperatures the deformation was concentrated into fewer slip lines indicating that the homogeneity of the deformation increases with increasing temperature. The crack initiation site was commonly the intersection point of a slip line and a boundary weakened by oxidation.

4. Slip line observations on the cross-sections of the L-samples fatigued at $950{ }^{\circ} \mathrm{C}$ show that the operative slip systems during cyclic straining are primary and critical slip systems. Also slip lines belonging to the cross or conjugate systems were found, but the Schmid factor in these systems is close to zero. Therefore it is concluded that these lines are a reaction product between the primary slip plane and the critical slip plane.

\section{References}

1. G. W. Meetham, "Superalloys in Gas Turbine Engines", Met. and Mat. Tech., 14(1982), 387-392.

2. 1. S. Benjamin, "Mechanical Alloying", Sci. Am. $234(5)(1978), 40-48$. 
3. Y. Kaieda, "Trends in Development of Oxide-DispersionStrengthened Superalloys", Trans. Nat. Res. Inst. Metals, 28(3)(1986), 18-24.

4. M. J. Fleetwood, Mechanical Alloying - The Development od Strong Alloys", Mat. Sci. Tech., 2(1986), 1176-1182.

5. H. Zeizinger and E. Arzt, "The Role of Grain Boundaries in High Temperature Creep Fracture of an Oxide Dispersion Strengthened Superalloy", Z. Metallkde., 79(1988), 774-781.

6. A. Hynnä, High Temperature Low Cycle Fatigue Behavior of ODS Superalloy MA 760 - Mechanical Behavior, Fracture- and Deformation Characteristics, Microstructural Changes and Dislocation Configurations, (Doctoral Thesis, Tampere University of Technology), Tampere University of Technology Publications 140 (Tampere, Finland, 1994), 98.

7. A. Hynnä, V. T. Kuokkala and P. Kettunen, "Mechanical Behavior of Superalloy MA 760 during High Temperature Cyclic Straining", (Paper to be presented at The Sixth International Fatigue Congress "Fatigue '96" Berlin, FRG, 6 - 10 May 1996).

8. A. Tekin, J. W. Martin, "Fatigue Crack Growth Behaviour of MA 6000", Mat. Sci. Eng., 96(1987), 41-49.

9. E. Arzt, "High Temperature Properties of Dispersion Strengthened Materials Produced By Mechanical Alloying: Current Theoretical Understanding and Some Practical Implications", New Materials by Mechanical Alloying Techniques, ed. E. Arzt and L. Schultz (Oberursel, FRG: Deutsche Gesllschaft für Metallkunde e.V., 1989), 185-200.

10. D. M. Elzey, E. Arzt, "Crack Initiation and Propagation during High-Temperature Fatigue of Oxide Dispersion-Strengthened Superalloys", Metall. Trans. A, 22A,(1991), 837-851.

11. D. M. Elzey, E. Arzt, "Oxide Dispersion Strengthened Superalloys: The Role of Grain Structure and Dispersion During High Temperature Low Cycle Fatigue", Superalloys 1988, ed. S. Reichman et al. (Warrendale PA: The Metallurgical Society, 1988), 595- 604.

12. V.-T. Kuokkala, "Indexing of Slip Line Patterns on Single Crystalline FCC Specimens" (Report Tampere University of Technology, Institute of Materials Science 62/1993), 7. 